\title{
CDISC SEND Distribution Terminology
}

National Cancer Institute

\section{Source}

National Cancer Institute. CDISC SEND Distribution Terminology. NCI Thesaurus. Code C120530.

Terminology associated with the distribution codelist of the Clinical Data Interchange Standards Consortium (CDISC) Standard for the Exchange of Non-clinical Data (SEND). 